experiences much larger plastic deformations than the faster one, which under lighter loads and with less ductile materials would be likely to lead to a shorter fatigue life.

The papers on rolling contact made it clear that stresses and distortions in rolling contact are likely to differ from those in a stationary contact under the same forces. Dr. Johnson explained this difference in terms of the different stress history of a surface element in the two cases. If either slip or plastic flow takes place, a difference in sequence of loading leads to a difference in the overall stress pattern. In particular, it was shown that slip at the contact surface begins at the trailing edge of the contact area and not at the leading edge. A method of approach to the theoretical problems of rolling contact was suggested in which the process is viewed as one of 'steady-flow' in the manner of hydrodynamics. This involves using the Eulerian co-ordinate system ${ }^{10}$ in which the contact region appears as a stationary pattern of elastic distortion through which the material of both surfaces flows at a steady rate.

Taken as a whole, the symposium gave a valuable co-ordinated view of the present state of research into contact problems in Britain. K. L. JoHNSON
PAPERS PRESENTED AT THE StMPOSIOM

Andrews, H. I., "Contact Stresses on Railways and Wheel and Rail Problems".

Ollerton, E., "Contact Stresses between Toroids under Radial and

Tabor, D.; "Effect of Tangential Stresses on Plastically Loaded Con-

Storey, C., "Point Contact Effects-the Relevance of Hertz's Theory". Gough, V. E., "Tyre to Ground Contact Stresses".

Milne, A. A., and Nicholson, A. M., "Pitting Failure-Some Studies in the Modfled Four-bail Machine". Crook, A. W. "Some Experiments upon Sub-surface Deformation in
a Disk Miachine".

Johnson, K. I., "The Rolling Contact of Elastic Solids viewed as a Steady-flow Process".

\section{REFERENCES}

${ }^{2}$ Mindlin, R. D., J. Appl. Mech., 16, Trans. A.S.M.E., 71, 259 (1949). 2 Poritsky, H., J. Appl. Mech., 17, Trans. A.S.M.E., 72, 191 (1950).

"Bowden, F. P., and Tabor, D., "Friction and Lubrication of Solids" (Oxford Univ. Press, 1950).

- McFarlane, J. S., and Tabor, D., Proc. Roy. Soc., A, 202, 224 (1950),

Courtney-Pratt, J. S., and Eisner, E., Proc. Roy. Soc., A, 288, 529 (1957).

- Johnson, K. L., Proc. Roy. Soc., A, 280, 531 (1955); Inst. Mech. Fng. Conf. Lubrication and Wear (1957), Paper 24.

7 Milne, A. A., and Nally, H. C., Inst. Mech. Eng. Conf. Lubrication and Wear (1957), Paper 54.

- Way, S., J. Appl. Mech., 2, Trans. A.S.M.E., 57, 49 (1935).

- Crook, A. W., Proc. Inst. Mech. Eng., 171, 187 (1957).

10 Bishop, R. E. D., and Goodier, J. N., J. Mech. and Phys. Solids, 2, 103 (1954).

\title{
THE METROPOLITAN-VICKERS IRRADIATION LABORATORY
}

$\mathrm{T}$

HE opening on May 29 of the new Irradiation Laboratory at the Metropolitan-Vickers Barton works was performed by Mr. H. West, director of electrical engineering in the Company. In a short address he reminded his audience that the scientific and engineering contributions made by MetropolitanVickers to the development of high-vacuum equipment and particle accelerators have been prominent in keeping Britain to the forefront in this field. An inspection of the new laboratory certainly gave strong support to his claim.

The principal item of equipment in the laboratory is the 4-MeV. linear accelerator, which produces the beam of irradiating electrons. There is nothing fundamentally new about this unit; it has been adapted from the accelerator developed by the Company for its 4-MeV. X-ray machines which are already installed in several hospitals in Britain. The electrons, bunched together into small clusters and travelling in a hollow corrugated' wave-guide, are accelerated by a radio-frequency field which is produced by the propagation of radio-frequency power of short wave-length (usually $10 \mathrm{~cm}$.) along the waveguide. The design of the wave-guide is such that the velocity of propagation of the radio-frequency field matches that of the accelerating electrons, so maintaining the phase relationship between field and beam and ensuring the continuous acceleration of the electrons along the whole length of the wave-guide. A radio-frequency feedback system is used to increase the energy of the beam, which is released in pulses of $2 \mu$ sec. duration at a rate of between 50 and 500 pulses per sec. The power of the beam is of the order of 500 watts, corresponding to a mean beam current of $125 \mu \mathrm{amp}$. At the output end of the accelerator an alternating field fans out the electrons so that they scan an area of 12 in. $\times \frac{3}{4}$ in. as they emerge from an aluminium foil window.

The construction of the laboratory itself leaves nothing to chance in the matter of safety. A system of interlocked doors ensures that access to the treatment room (surrounded by massive concrete walls with 4-in. steel plates at strategic locations) or to the accelerator room automatically renders the apparatus harmless. All the control equipment is centralized and is well clear of any radiation or high-voltage hazard. Articles to be irradiated may be mounted either on a variable-speed continuous conveyor belt or a specially designed work-table, both of which are operated by remote control.

The property which makes irradiation a useful process is the disruption which it causes, particularly in large molecules. When biological systems are irradiated, three types of change may occur. Slight irradiation will lead to no obvious damage to the organism, but through the agency of gene mutation may promote the evolution of new genetic types. This offers the interesting passibility that, by exposing quantities of seed to radiation, the probability of producing mutations and of occasionally finding some improved plant strain may be greatly increased. Greater doses of radiation may render sterile the irradiated organism. A suggested application of this property is the improvement of the storage properties of some vegetables, such as potatoes, by preventing them from sprouting.

However, the most fascinating possibilities seem to arise from the utilization of the lethal effects of very large doses of radiation as a bacteriocide. Foodstuffs which normally deteriorate through bacterial infec. tion have their keeping properties much improved 
by irradiation; unfortunately, the dosage required to exterminate the bacteria sometimes renders the food unpalatable, a difficulty which has still to be overcome. An even more attractive application is in the sterilization of certain types of pharmaceutical products; due to chemical instability or unfavourable physical properties, it may not be possible to use the usual high-temperature methods of sterilization, and irradiation may be used with a temperature rise of a few degrees only. In addition, the product may often be treated in its finally packaged state, ready for distribution.

The irradiation of polymeric substances frequently results in useful changes of their properties. These changes may be roughly classified into two types. In the first of these $\mathrm{C}-\mathrm{H}$ bonds are ruptured to give a hydrogen atom and a free polymer radical. Two radicals combine to give a larger molecule, a process known as cross-linking, and a molecule of hydrogen is liberated. If the irradiation dosage is large, so many cross-linkages may be formed that the whole specimen becomes virtually a single huge molecule which is extremely inert chemically and insoluble in most solvents. The other type of change which may occur is known as degradation. The polymer is broken down into simpler hydrocarbons, some of which are gaseous and held in the substance under high pressure. Subsequent heating of the polymer softens it and allows this gas to expand, thus producing a foamed material the low density and other characteristic properties of which have found useful applications.

The new laboratory has been set up by Metropolitan-Vickers to provide an irradiation service for other industrial firms and organizations. In doing so the Company has demonstrated a degree of initiative which one hopes will be matched by its potential customers. It is pleasant to witness an industrial enterprise which is not content merely to keep abreast of current scientific advance but which also itself makes a noteworthy contribution to scientific progress.

\section{THE PROGRESS OF WORLD HEALTH}

$\mathrm{O}$ $\mathrm{N}$ April 7 the World Health Organization marked its tenth anniversary by sponsoring the celebration, on that date, of a World Health Day in London. As its director-general, Dr. M. G. Candau, said, there have been, during the past ten years, great scientific advances-new drugs, new vaccines, new and better insecticides, more effective methods of fighting or preventing disease. Governments have learnt to take responsibility for the health of their peoples and to provide not only hospitals and health institutions, but also better food and better care fo mothers and the young; and eighty-eight countries are now members of the World Health Organization.

How much has been achieved was outlined by Dr. H. van Zile Hyde, chief of the United States Division of International Health. Infectious disease has handicapped man throughout his history. History has, in fact, often been changed by diseases such as typhus, influenza, plague and malaria. But in limited areas of the world in which it has been possible to apply the knowledge acquired by medical science, the epidemics of the past - cholera, smallpox, plague and yellow fever-are no longer feared. Malaria, prevalent in regions in which three-fourths of mankind live, has been conquered to such an extent that whereas, in 1948,300 million people had malaria each year and 3 million died of it, these figures have to-day been cut by 30 per cent. This disease is still one of the most formidable menaces, but its eradication, already achieved in certain areas, is now possible almost everywhere in the world. It is likely that it will, in a few years, be controlled in the United States, and no new infections with it are expected in the U.S.S.R: after 1960. In the eastern Mediterranean, a traditional reservoir of the disease, great progress in its control has been made. The most serious problem is presented by Africa south of the Sahara, but here also much has been achieved.

The list of other scourges controlled is long and encouraging. Respiratory diseases, such as pneumonia, the common cold and influenza, still flourish ; but whooping cough, though it still resists, is in retreat. The international spread of epidemic diseases, formerly controlled by quarantine regulations which imposed great hardships and delays in travel and commerce, is now reduced, in spite of increased possibilities of spread of these diseases by the aeroplane, to the relatively easy conditions of the International Sanitary Regulations designed by the World Health Organization and adopted in 1951 .

Many diseases formerly feared, such as cholera, typhus, smallpox, yellow fever, tuberculosis, and those menaces of childhood, scarlet fever, measles and diphtheria, are now virtually under control and, if they occur and are properly handled, they rarely kill. The decline of mortality is, in fact, one of the most significant features of the health record of the world, but it creates new problems that are serious. More elderly people must be fed and housed and given work ; the diseases of later life, such as cancer, diabetes and heart disease, are commoner. The stress of modern life is also taking its toll, and great quantities of drugs are manufactured to counter this stress. Whereas infectious and parasitic diseases have been reduced by half, accidents, especially among the young, are leading causes of death. For the very young, on the other hand, and for the mothers who bear them, there is much greater chance of health and happy life.

Thus people born nowadays may expect, apart from accidents, a safer, longer and happier life than earlier generations could. They owe this, of course, primarily to the work of men and women of all nations who have provided the knowledge on which this remarkable progress has been based, and also to the work of the World Health Organization and kindred organizations which have integrated and correlated the work done by individuals and teams in various parts of the world. A major problem of the future would seem to be the diseases of later life, such as cancer, diabetes and arteriosclerosis. If so much has been done in a decade, there is every hope that these diseases also will soon be added to the list of scourges that man has overcome.

G. Lapage 